\title{
Using Micro-Video ProJects in LARGE EngineERING Classes to Differentiate ASSESSMENT
}

\author{
Jeffrey Erochko \\ Carleton University \\ jeffrey.erochko@carleton.ca
}

\begin{abstract}
A$ new assessment tool is introduced that uses one minute long, individual micro-video presentations to give students an opportunity to demonstrate mastery of specific engineering concepts orally instead of in the typical written form. The short time-frame of the videos requires students to think critically about the concept and to explain it concisely. It also reduces assessment time, allowing teaching assistants to grade it quickly, even in a large class.

Three micro-video projects were implemented in a third year and fourth year civil engineering course at Carleton University with 180 and 96 students, respectively. The format of the micro-video tool is discussed in detail, including the assessment rubric that was used. Three anonymous elective student surveys were conducted at different stages to solicit student opinions. Students generally thought that the micro-video assignment was valuable, enjoyable, and provided a fair evaluation of their understanding.
\end{abstract}

Keywords: video, multimedia, oral assessment, YouTube, presentation, differentiated assessment, large classes.

\section{INTRODUCTION}

Anecdotal evidence suggests that written assignments, tests and exams are by far the most common assessment tools that are used in 'hard' undergraduate engineering courses (i.e. courses that focus primarily on calculations). In fact, in many courses, these three types of assessment tasks may, together, constitute the entirety of a student's final grade. This may have the effect of biasing the course assessment in favour of students who excel at those types of tasks. This is in spite of the fact that the method of assessment itself does not necessarily replicate the application of the skill in practice. For example, in practice, an engineer may not have an arbitrarily limited amount of time to design a structural beam.

Even in the cases where the method of assessment does reasonably replicate the practical application of the learned skill (for example, designing a structural beam on a take-home assignment), assignments, tests and exams do not in themselves, represent all of the situations that an engineer will encounter in practice. For example, in practice engineers may be expected to orally explain concepts of structural behaviour to peers or clients, a skill which may not be assessed in a design-focused course.

Some students may excel at the oral explanation of a concept, yet only perform adequately when asked to explain the same topic in a written form on a test or exam when there is significant pressure to perform. Just as students have different preferences for the way that they learn, they similarly have preferences for the way that they are assessed [3]. Therefore, it seems clear that if assessment methods seem too uniform, then educators should try to differentiate assessment practices to cater to a wider range of student learning styles.

In fact, the Canadian Engineering Accreditation Board (CEAB) graduate attribute criteria specify that students should be explicitly assessed for their Communication Skills, including "an ability to communicate complex engineering concepts within the profession and with society at large." [4] This attribute may not often be assessed within 'hard' courses, but instead may be relegated to only the 'softer' courses in the curriculum that deal specifically with communication skills; however, it may be valuable to inject elements of communication throughout the curriculum in order to avoid giving students the impression that the communication and technical aspects of engineering are somehow separate.

Of course, for assessment it would be ideal to be able to have a detailed one-on-one discussion with every student in a course to assess their understanding of course concepts. Indeed, such an assessment may be possible for small classes in which the instructor has the resources to individually interact with every student. A common alternative option, which includes some aspect of oral communication into a course, is to assign students an individual or group oral presentation within class to assess how well a student can explain a learned concept; however, such presentations are not typically practical in classes that have over 100 students. Even in mediumscale classes with fewer than 100 students, where oral 
presentations may be possible as a method of assessment, it is probable that presentations would have to be developed and performed in groups to allow all students to participate. This provides additional challenges related to the ability of the instructor to assess the performance and contribution of individual students.

In recent years, particularly since the widespread use of YouTube and other video-sharing services, students and educators have had more tools available for facilitating oral communication. The debate over the myth of the 'digital-native' notwithstanding [2], it is certainly the case that video-sharing services and video creation hardware have become so user-friendly that they are practically accessible to anyone. Based on the current study, it seems to be a safe assumption that in Canada, students have access to some device that can record a simple video (such as a webcam or smartphone) and are able to upload a video to YouTube or a similar service.

Educators around the world are currently experimenting with video creation assignments in higher education. Green [6], in an MBA elective course, had students create an 8-10 minute speech on YouTube and had them post the resulting video on an online course discussion forum for feedback from peers. This concept takes the traditional oral presentation concept and extends it using video technology to increase the opportunity for feedback. It also allows online course participants to partake in an oral presentation experience. Cox et al. [3], in a small second-year seminar, had groups of students create three minute 'multimedia objects' where they answered an open ended question with a creative video on YouTube or in PowerPoint. The assessment of these videos included both the final product and a process mark, with both individual and group mark components. Baepler and Reynolds [1], also used short 3 minute student videos in a small seminar writing course to assess 'multi-modal' thinking by creating a visual companion to a written manifesto. Likewise, Zahn et al. [7], used 4-5 minute student-created YouTube videos in a seminar course. The goal of their study was to reduce the stigmatization of obesity. The project was found to be effective at reaching that goal. In all of the above studies, the use of video presentations was found to increase student engagement with the course material; however, none of these concepts is specifically applicable to larger class sizes.

In contrast, Franz [5] used short videos in a large organic chemistry class of 300-400 students. In this project, student groups of two to five had to create a script for a YouTube-style video creatively explaining an organic chemistry concept. Submitting an actual video was optional for extra credit. Students were assessed as a group and student engagement with the project was good.

The current study introduces a new method of individual oral assessment called the micro-video project that may be used in large university courses. This format uses a one-minute 'talking-head' style video in which students are tasked with explaining a course concept in less than one minute. The focus of the assessment is on clarity of explanation and technical understanding, with no focus on creativity or the quality of the video itself. This requires students to think critically about the concept and explain it concisely without having to focus on the technical aspects of video production. The short format of the videos also allows it to be assessed by teaching assistants in a large class using a simple rubric and within a reasonable amount of time. The use of this micro-video project allows some level of differentiated assessment by introducing evaluation based on oral explanations and may also contribute to the CEAB graduate attributes for Communication Skills.

The project was implemented in two different courses in the Department of Civil and Environmental Engineering at Carleton University, with class sizes of 180 students and 96 students. Student attitudes about the project were solicited through the use of an anonymous feedback survey and the results of this survey will be presented below.

Although the application of the micro-video project in this study was based on differentiating assessment in 'hard' engineering courses, this concept is expected to also be widely applicable in other engineering courses, or in other disciplines where there may be a desire to differentiate assessment in a large class.

\section{THE MICRO-VIDEO PROJECT}

\subsection{Learning Objectives}

The goal of the micro-video project is to provide a quick and simple way to assess the ability of students to explain a technical concept clearly and concisely in their own words. The goal is not to teach students how to use YouTube or how to create engaging videos. The project is treated as a surrogate for an in-person oral assessment or examination and is structured to minimize additional student workload. Students should be able to individually complete the entire assignment in a couple of hours. As such, the quality of the video itself is not emphasized in the project description provided to students. Therefore, there is no requirement for students to be creative and they are encouraged to simply sit in front of the camera and explain their concept in a 'talking-head' format.

Consistent with the goal of treating the micro-video project as a surrogate for an oral exam, the results of the video are not shared with the rest of the class. Students are told explicitly that the only people to view their video will be the instructor and the teaching assistants (unless the student chooses to make their video public on YouTube). The reason for this is to reduce the level of 
student stress typically associated with in-class presentations.

Students are given a short time limit on their video for two reasons. First, it forces them to be concise with their explanation, which typically requires some planning and forethought before recording the video. Second, it allows the videos to be assessed quickly by teaching assistants. If videos are 1:30 min, then 200 videos can be assessed by a single teaching assistant in under eight hours, which is significantly less than the time required to assess a quiz or assignment for the same number of students.

\subsection{Project Format}

Students are provided a project handout which explains both the structure and requirements of the project as well as the assessment rubric that will be used to evaluate them. Students are given approximately two weeks to complete the assignment.

Students may use any video recording device to create their video as long as the resulting video may be uploaded to YouTube. YouTube is used for convenience since the learning management system (LMS) at Carleton, which is Moodle-based, does not currently have the capability to receive student video submissions. Instead, an online quiz was created in Moodle where students simply paste a link to their YouTube video. It is recommended that the students choose to make their video unlisted on YouTube, meaning that the video is only available to someone who has a direct link (it is not searchable).

Since YouTube is an outside company that requires some information from students in order for them to use it, an opt-out mechanism is provided for students in case they are not comfortable with using YouTube. Students who choose to opt-out must attend a short oral examination in-person with the instructor where they would explain the same topic that they would have explained on the video. No student has yet chosen to optout of the online video.

At the beginning of the video, students are required to state their name, the name of the course, and the topic that they have chosen for their video. In the first implementation of the micro-video project, there was only one possible topic for the video. Based on student feedback, later implementations of the project provided a choice of two or three different engineering concepts that the students could choose to explain. Students are instructed to explain the concept in their own words, that they may not use the same explanation as someone else, and that they may not read an explanation from a book or set of notes. Students are permitted to prepare their own explanation in written form and then read it in front of the camera.

\subsection{Assessment}

The micro-video project is assessed using a simple rubric as shown in Table 1 below. The total mark is out of a maximum of six points. The most weight is given to the student's demonstrated understanding of the engineering concept. Additional marks are assigned to the clarity of the explanation, which assesses their oral presentation skill, and completeness, which assesses their ability to respond to instructions.

Table 1: Micro-Video Project Assessment Rubric.

\begin{tabular}{|c|c|}
\hline Completeness & Weight $=1$ \\
\hline \multicolumn{2}{|c|}{$\begin{array}{l}1 \text { - All submission requirements have been met } \\
0 \text { - One or more submission requirements are not met }\end{array}$} \\
\hline Clarity & Weight $=2$ \\
\hline \multicolumn{2}{|c|}{$\begin{array}{l}2 \text { - The student speaks clearly and confidently. } \\
1 \text { - The student is not always completely intelligible or } \\
\text { talks too fast to be understandable. } \\
0 \text { - The student mumbles and is difficult to follow. }\end{array}$} \\
\hline Understanding & Weight $=3$ \\
\hline \multicolumn{2}{|c|}{$\begin{array}{l}3 \text { - The student demonstrates a clear understanding of } \\
\text { the topic. } \\
2 \text { - The student has a good understanding of the topic } \\
\text { but may make some minor conceptual errors. } \\
1 \text { - While the student appears to have a general } \\
\text { understanding of the topic, she/he is not able to } \\
\text { demonstrate the understanding. } \\
0 \text { - The student does not demonstrate any } \\
\text { understanding of the topic. }\end{array}$} \\
\hline
\end{tabular}

\subsection{Implementation}

The micro-video project has been implemented in two different courses in the Department of Civil and Environmental Engineering at Carleton University, both taught by the author. The first is a third year compulsory course in structural analysis with 180 students (CIVE3203), and the second is a fourth year elective course in wood engineering with 96 students (CIVE4202). In each course, there were two micro-video projects assigned during the term, together making up a total of $10 \%$ of the students' final mark $(5 \%$ for each project). The micro-video project was a mandatory assignment in both courses.

The project was implemented in the structural analysis course first (CIVE3203). The first time the project was assigned in CIVE3203, the time limit for the videos was 60 seconds and there was only one question: "Explain one way that a structure may be unstable or become unstable." Based on student feedback, the second project in CIVE3203 had a slightly increased time limit of 75 seconds and a choice of two different questions: (1) "Explain, in brief, why the force method works" or (2) 
"Explain how to use the Muller-Breslau Principle to construct an influence line for a reaction, internal shear or internal moment (just one of these, not all of them)." The feedback that led to these changes will be discussed in detail in the next section. In this course, feedback surveys were conducted after each micro-video project was complete.

Following a reasonably successful implementation in the structural analysis course, in the following term the micro-video projects were used in the wood engineering course (CIVE4202). The first project had a time limit of 75 seconds and students had a choice of two questions: (1) "Explain the cellular structure of wood" or (2) "Explain one mechanism for the degradation of wood structures in service." Following feedback again from the students, the second project in CIVE4202 had a slightly longer time limit of 90 seconds and had a choice of three different questions: (1) "Explain viscoelasticity and how it affects the strength of wood," (2) "Explain the function of each term in the combined axial compression and bending equation (5.5.10)," or (3) "Explain the justification behind the use of the bearing factor $K_{B}$ (5.5.7.6)." For this course, there was only one feedback survey conducted after the first project.

\section{SURVEY METHODOLOGY}

Three anonymized student response surveys were conducted to solicit feedback from students about the micro-video project. The surveys were conducted using the learning management system at Carleton (cuLearn) which is based on Moodle. This system has a built-in feedback survey function which has the ability to anonymize the results. The Carleton University Research Ethics Board reviewed and approved the study, and students were informed that the data would be used for research purposes. Students were encouraged to participate but it was made clear that the instructor would not know who had participated and that participation would have no bearing on their course evaluation.

The surveys each consisted of 8-10 multiple choice questions, which varied slightly between the surveys, and two written response questions, the first being "What do you like about the video assignment?" and the second being "What would you change about the video assignment?" This paper will focus primarily on the results from the multiple choice questions on the surveys. The posed questions for each survey will be presented alongside the response data in the following sections.

The response rates for the three surveys were: CIVE3203 Project 1 (P1): 48 out of 180 (26\%), CIVE3203 Project 2 (P2): 54/180 (30\%), CIVE4202 Project 1 (P1): 50 out of 96 (52\%).

\section{SURVEY RESULTS}

\subsection{Use of Technology}

Although this micro-video assignment does not focus on the quality of student videos, students must use both video recording and online video hosting technology to complete the project. One of the primary concerns with this is whether the students would encounter technical difficulties in creating or submitting the videos. Figure 1 shows the survey results for the question: "I experienced technical problems with submitting the micro-video project." The data shows that the vast majority of students did not have any difficulties using YouTube to upload the video. Only $10-11 \%$ of students had trouble, and a number of these responses likely represent students who tried to submit the link for the video after the deadline because they did not take into account the amount of time it takes to upload the video.

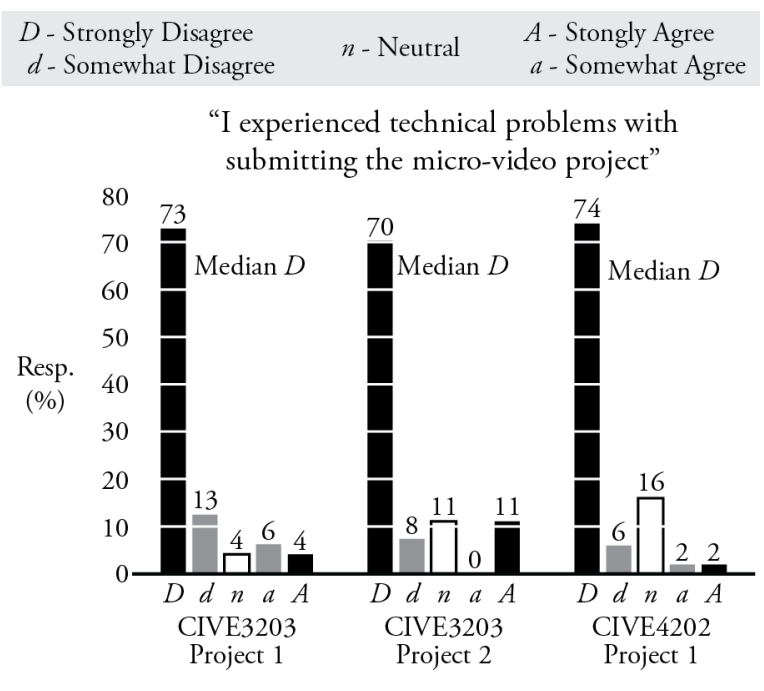

Fig. 1. Student attitudes regarding technical problems associated with submitting the project.

\subsection{Specificity of the Questions}

Figure 2 shows survey results related to the specificity or flexibility in the question topics. The issue of specificity and flexibility was posed to two opposite ways to determine whether the questions were achieving an appropriate balance. The survey data in Fig. 2 shows that the median response for all of the questions for all of the projects was neutral, showing that the questions seemed to generally strike a good balance; however, the questions were gradually made more specific on the later projects (the questions were provided in Section 2.4), which seemed to create a more balanced distribution of responses the first question in Fig 2 for CIVE4202 Project 1 (the most recent project).

Flexibility was added to the project by adding multiple questions to each project, thus providing students with an 
option of which question they would answer. CIVE3203 P1 had only one choice, CIVE3203 P2 and CIVE4202 P1 both had two choices. Even with two choices, the students in CIVE4202 seemed to want more, so the second project in that course had three choices (not shown). The median for all of the projects was neutral, showing that, in general, students were satisfied with the amount of choice and flexibility.

$D$ - Strongly Disagree
$d$-Somewhat Disagree $\quad \begin{aligned} & \text { - Neutral } \\ & A \text {-Stongly Agree } \\ & a \text {-Somewhat Agree }\end{aligned}$

"I would like the micro-video project question to be more specific"

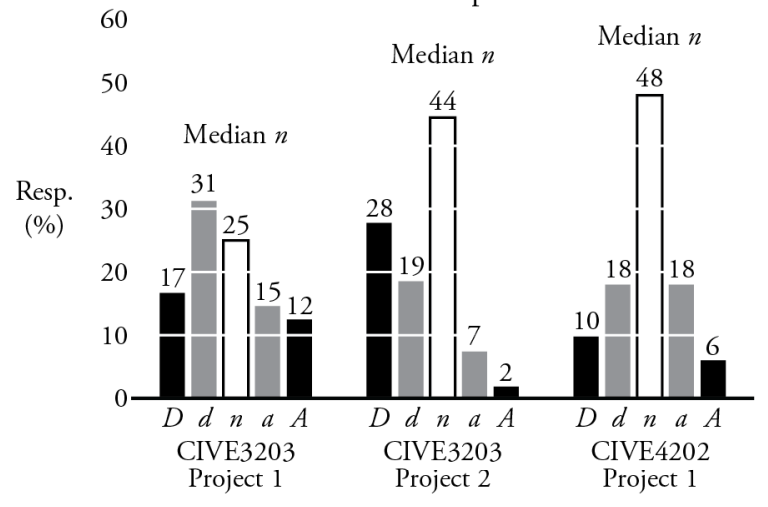

"I would like more flexibility in the topic/question for the micro-video project"

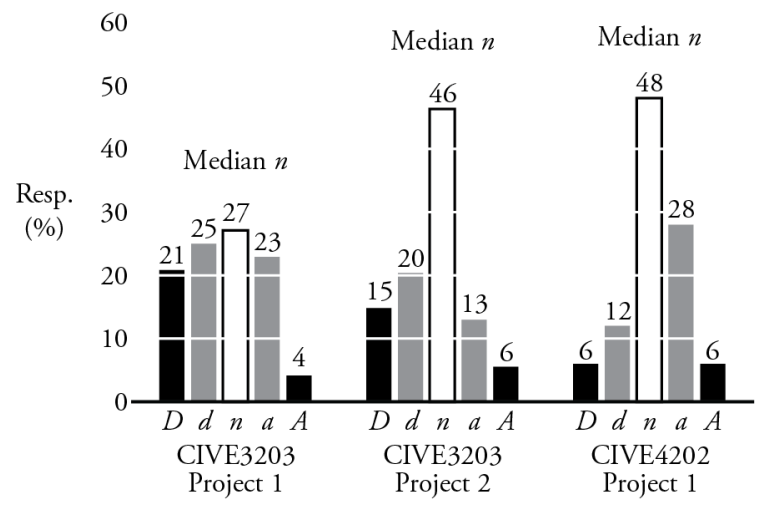

Fig. 2. Student attitudes regarding the specificity of the available project topics / questions.

\subsection{Level of Difficulty}

Figure 3 shows survey results related to the difficulty of the micro-video project. The first question in Fig. 3 shows that students generally find the video project to be somewhat easy. No students found the projects to be 'very challenging'. Based on the results from the first CIVE3203 project, an attempt was made to make the questions more difficult for the second project.

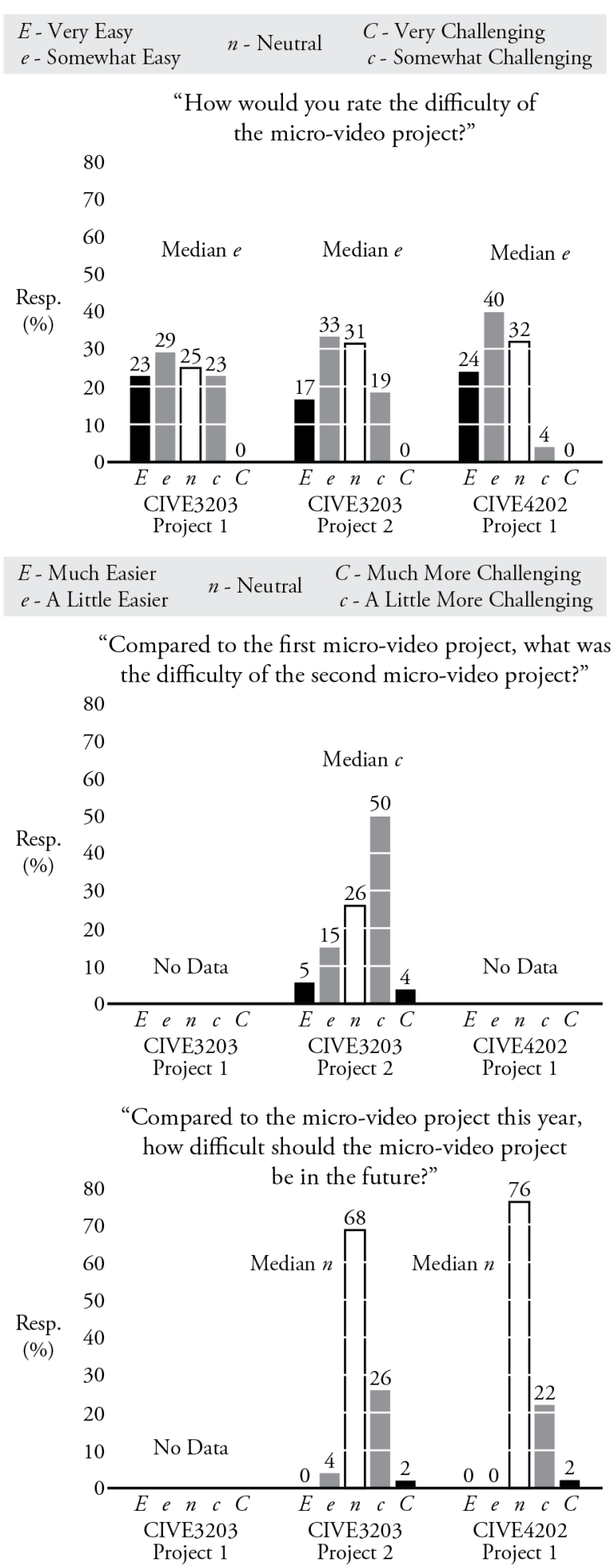

Fig. 3. Student attitudes regarding the difficulty level of the project.

The results for the second question in Fig. 3 show that students did find P2 more difficult than P1, even though 
the results for the first question are not very different for $\mathrm{P} 2$ versus $\mathrm{P} 1$.

The third question in Fig. 3 asks whether the project should be made more difficult in the future. While the median response for this question was neutral, students do seem to suggest that the project could be improved by making it more difficult. Even so, students seem to like the current level of difficulty.

\subsection{Video Length}

Figure 4 shows survey results related to the video length for the micro-video project. Project 1 in CIVE3203 was 60 seconds long. Based on the feedback shown in Fig. 4, P2 was 75 seconds long, which seemed to match student preferences better. In CIVE4202 P1, the video was 75 seconds long and students seemed to think that was still a bit short, although very few students thought the video should be longer than 90 seconds. Of course the appropriate amount of time for the assignment depends on the questions that are asked; however, based on this feedback, it seems that students believed that $60-90$ seconds is a reasonable amount of time for the project videos.

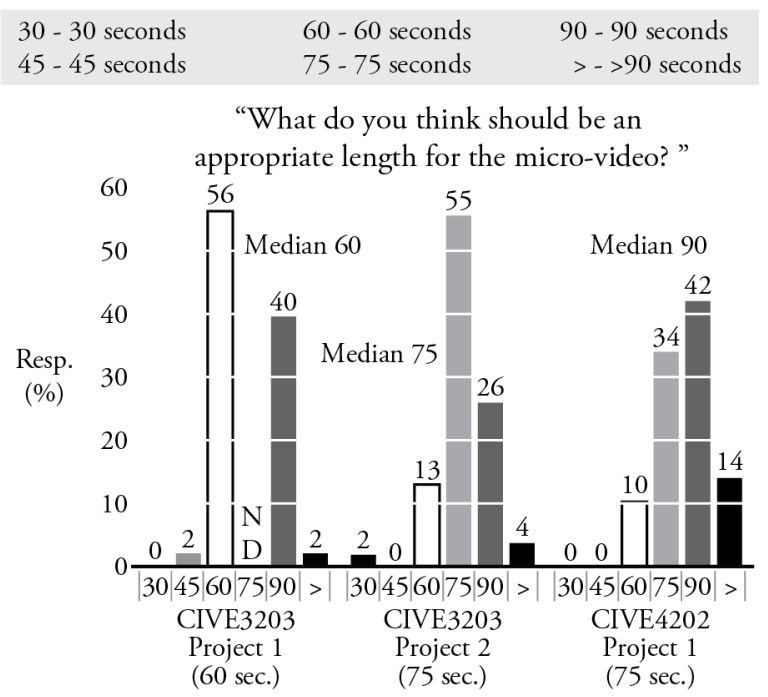

Fig. 4. Student attitudes regarding the time length of the video.

\subsection{Student Attitudes Regarding Project Value}

Figure 5 shows survey results related to whether students thought that the micro-video project provided a fair assessment of their understanding of the specific concept covered by the question they chose. Only $12 \%$ of students were at all dissatisfied with the micro-video project as a method of assessment.

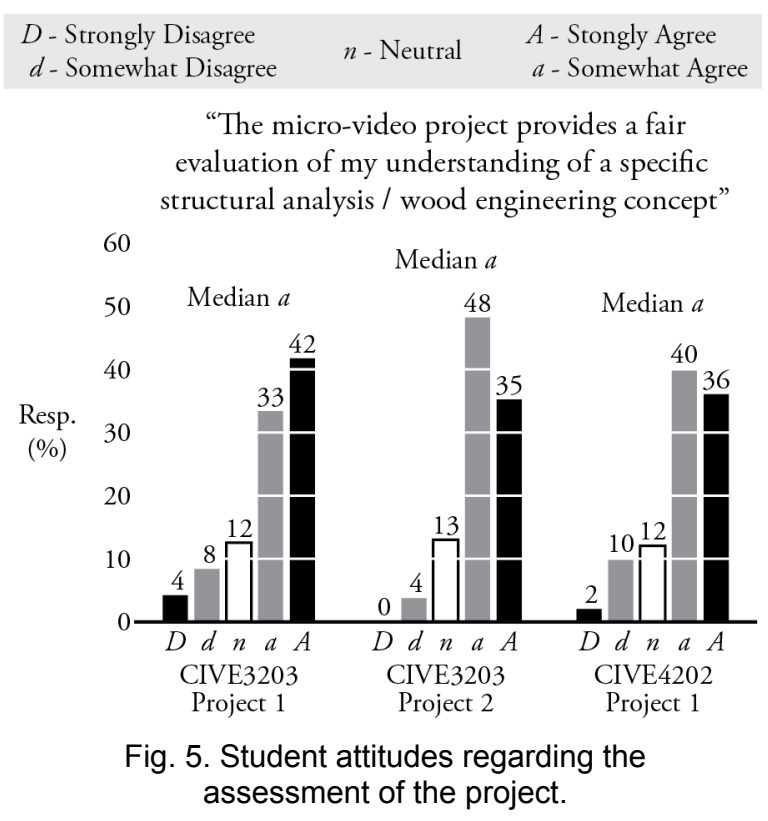

Figure 6 shows that, generally, students both enjoyed doing the project (83\% enjoyed it in CIVE3203 and 58\% enjoyed it in CIVE4202) and felt that it was a valuable learning experience $(79 \%$ by the end of the term in CIVE3203 and $62 \%$ in CIVE4202).

Figure 7 shows that, by and large, students would suggest continuing with the micro-video project in the future, with only $7 \%$ in CIVE3203 and $18 \%$ in CIVE4202 suggesting that the project should not continue.

In general, the students in the mandatory CIVE3203 class seemed more satisfied with the project than those in the elective CIVE4202 class. The differences here may be due to the different demographics of the students in the two courses, with CIVE3203 having all of the third year civil engineers, and CIVE4202 having only a subset of the students in fourth year. It may be the case that students are more receptive to these kinds of alternative assessment methods if they are introduced earlier in their degrees.

\section{CONCLUSIONS}

A new method of assessment called the micro-video project has been presented. This project allows for the oral assessment of students in large classes, based on their spoken answers to specific conceptual questions provided by the instructor. The project was implemented in two different civil engineering courses. 


$$
\begin{aligned}
& D \text { - Strongly Disagree } \\
& d \text {-Somewhat Disagree }
\end{aligned} \quad \begin{aligned}
& A \text { - Neutral } \\
& a \text {-Stongly Agree } \\
& \text {-Somewhat Agree }
\end{aligned}
$$

"The micro-video project has been valuable to my learning experience in this course"
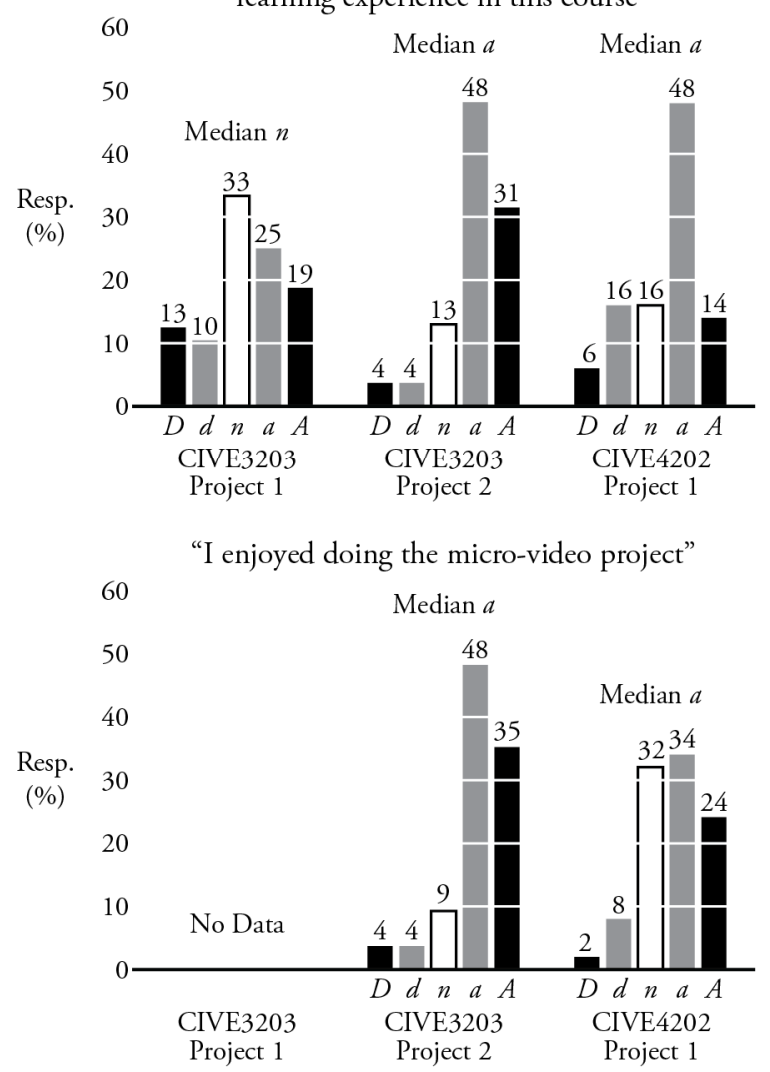

Fig. 6. Student attitudes regarding the learning experience and enjoyment of the project.
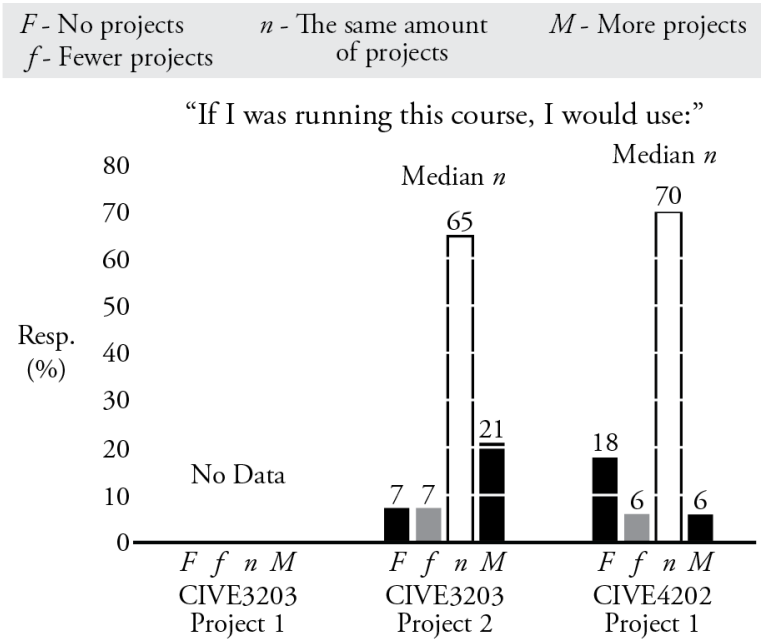

Fig. 7. Student attitudes regarding the use of a micro-video project for future courses.
Anonymous student surveys were conducted to assess the projects. These surveys found that students generally did not experience technical problems submitting the videos, the level of specificity of the questions and the length of the videos were appropriate, and the questions may have been a bit too easy. Students generally felt that the project provided a fair assessment of their learning, was a valuable learning experience, and was enjoyable to do.

Based on this feedback, the micro-video project seems to be a valuable assessment tool for use in large classes. It provides instructors with a way to differentiate their assessment, giving students an alternative way to prove their mastery of course content outside of traditional tests and written assignments.

\section{References}

[1] Paul Baepler and Thomas Reynolds, "The Digital Manifesto: Engaging Student Writers with Digital Video Assignments," Computers and Composition, vol. 34, pp. 122-136, December 2014.

[2] Sue Bennett, Karl Maton, and Lisa Kervin. "The 'digital natives' debate: A critical review of the evidence," British journal of educational technology, vol. 39, no. 5, pp. 775786, September 2008.

[3] Menucha Birenbaum. "Assessment preferences and their relationship to learning strategies and orientations," Higher Education, vol. 33, no. 1, pp. 71-84, January 1997.

[3] Andrew M. Cox , Ana Cristina Vasconcelos and Peter Holdridge, "Diversifying assessment through multimedia creation in a non-technical module: reflections on the MAIK project," Assessment \& Evaluation in Higher Education, vol. 35, no. 7, pp. 831-846, December 2010.

[4] Engineers Canada, Canadian Engineering Accreditation Board: Accreditation Criteria and Procedures. Ottawa, ON: Engineers Canada, 2014, 118 pp. \{ISSN1708-8054\}

[5] Annaliese K. Franz, "Organic Chemistry YouTube Writing Assignment for Large Lecture Classes," J. Chem. Educ., vol. 89, no. 4, pp. 497-501, March 2012.

[6] David T. Green, "Using Student Video Presentations in an Online Course," Decision Sciences Journal of Innovative Education, vol. 6, no. 2, pp. 521-526, July 2008.

[7] Carmen Zahn, Norbert Schaeffeler, Katrin Elisabeth Giel, Daniel Wessel, Ansgar Thiel, Stephan Zipfel, and Friedrich W. Hesse, "Video clips for YouTube: Collaborative video creation as an educational concept for knowledge acquisition and attitude change related to obesity stigmatization." Education and Information Technologies vol. 19, no. 3, pp. 603-621, September 2014. 